\title{
Quality of life of participants and non-participants of public physical exercise programs
}

Fabrício Ramalho da Costa'

Flávia Melo Rodrigues'

Cejane Oliveira Martins Prudentel

Ismael Franco de Souza'

Abstract

Objective: to compare the quality of life of elderly participants and non-participants of public physical exercise programs. Method: a control, analytical and cross-sectional study analyzing 108 elderly participants of public exercise programs (SG) and 126 non-participants (CG) in the city of Goiânia, Goias, Brazil, was performed. An initial Assessment Form, the Mental State Mini-Exam, the short version of the International Physical Activity Questionnaire, the World Health Organization Quality of Life - Bref (Whoqol-Bref) and the World Health Organization Quality of Life - Old (Whoqol-Old) were used. Comparison of socio-demographic profile and health conditions was performed using the Chi-squared test, while comparison of the quality of life of the SG and the CG was performed using covariance analysis (ANCOVA), followed by the post-hoc Tukey test. Results: the elderly persons in the SG had higher mean scores than those of the CG in all the Whoqol-Bref and Whoqol-Old domains $(p<0.05)$. The active elderly in the CG did not exhibit differences in relation to the insufficiently active or sedentary members of the CG for any Whoqol-Bref or Whoqol-old domain ( $p \geq 0.05)$. Conclusion: the elderly participants in public physical exercise programs had a better perception of quality of life than non-participating elderly persons, and it was found that simply being active may not be enough to guarantee a better quality of life.

\footnotetext{
Pontifícia Universidade Católica de Goiás, Programa de Mestrado em Ciências Ambientais e Saúde. Goiânia, GO, Brasil.

Keywords: Elderly. Quality of Life. Exercise. 


\section{INTRODUCTION}

The number of elderly persons has increased in most countries ${ }^{1}$, including Brazil ${ }^{2}$. With advanced age comes a decline in physical capacity, subsequently affecting performance when carrying out several tasks, including activities of daily living ${ }^{3}$. In addition to this decline, many elderly persons suffer from chronic non-communicable diseases ${ }^{4}$. Such comorbidities can result in a disabled condition, social isolation and also depression ${ }^{5}$.

Faced with such a reality, it is essential to maintain positive standards of health and quality of life, ensuring that longevity is accompanied by satisfactory levels of autonomy and independence ${ }^{6}$. For the World Health Organization (WHO), the concept of quality of life is understood as the individual's perception of their position in life within the context of their culture and the value system of where they live, and in relation to their own goals, expectations, standards and concerns?

Several studies have recently been carried out to understand the factors that can influence the quality of life of the elderly ${ }^{8-15}$. Previous studies have demonstrated that a physically active lifestyle and the regular performance of physical exercise are associated with various domains of quality of life, suggesting that the promotion of such activities can have a satisfactory impact on the functional capacity, mental health and quality of life of the elderly ${ }^{9,16,17}$.

The Brazilian National Policy on Health Promotion, published in 2006, recognizes the importance of physical activities and practices involving the body in reducing health risks and improving the quality of life of individuals ${ }^{18}$. This importance is also recognized internationally, causing scientific institutions from various countries to develop guidelines for activities and physical exercises for the elderly ${ }^{19,20}$.

Despite the evidence and recognition of the need to implement public policies for the promotion of physical activity in Brazil, few studies have analyzed the quality of life of elderly people who participate in public exercise programs. The objective of this study was therefore to compare the quality of life of elderly participants and non-participants of public physical exercise programs.

\section{METHODS}

A cross-sectional, analytical, case-control study with a quantitative approach was performed, based on interviews with elderly participants in the physical exercise programs of the Municipal Tourism and Leisure Events Agency (AGETUL) in Goiânia, Goiás, Brazil and elderly people who did not participate in exercise programs.

In 2016 AGETUL offered two physical exercise programs, An Active Life in Old Age and Healthy Walking, distributed in 18 neighborhoods of the city of Goiânia, with twenty activity nuclei. In each nucleus classes were offered in Functional Training, Group Gymnastics and walking, aimed at the general population, with weekly frequencies of two to five times and sessions of 60 minutes.

A minimum sample size was calculated considering the elderly population that frequented the AGETUL exercise programs in 2016. A sample error of $6 \%$ with a $95 \%$ confidence level was applied. The study sample consisted of a study group (SG), consisting of AGETUL elderly persons, and a control group (CG) made up of elderly community members who did not participate in any exercise-oriented activities.

Participants in the study who attended another physical exercise program, who had an attendance frequency lower than $75 \%$ in the six months before the data collection date, or who did not reach a minimum score in the Mini-Mental State Exam (MMSE), according to their degree of schooling, were excluded from the study (21). In addition to the SG criteria, individuals who participated in any exercise program in the six months preceding the date of data collection were also excluded from the CG.

AGETUL registration data were used to select the elderly in the SG, and the nuclei of the Agency with the highest number of elderly persons were visited until the minimum sample was reached, with a final total of six sites. Prior contact was made with those responsible for the activities of the selected nuclei to schedule a date and time for data collection. On the day of the visit, the objectives and procedures of the research were explained to the elderly persons, and a Free and Informed Consent Form (FICF) was given 
to each individual. Those who agreed to participate in the study returned a signed copy of this document before responding to the instruments.

CG recruitment was carried out after the collection of data in the nuclei. Letters of invitation were sent to elderly persons in the community who lived close to programs. This letter was left in residences, houses and apartments, and elderly persons who expressed an interest were contacted and data collection scheduled until the required quantity was reached. On the day of the visit, the elderly of the CG received an explanation of the research objectives and procedures and signed the FICF.

The data collection procedure began with the application of an initial Assessment Form, prepared by the authors themselves, which provided anthropometric, health status and sociodemographic variable information. Soon after an evaluation of cognitive state was performed using the MMSE ${ }^{21}$. Then the level of physical activity of the elderly was verified using the short version of the International Physical Activity Questionnaire (IPAQ), validated for the Brazilian population ${ }^{22}$, classifying them as insufficiently active or sedentary (IAS) and active ${ }^{13}$.

Afterwards, the perception of quality of life was evaluated using two instruments. The first was the Portuguese version of the World Health Organization Quality of Life-Bref (Whoqol-Bref) questionnaire validated for the Brazilian population ${ }^{23}$, which is composed of 26 questions. The first question refers to how the individual assesses their quality of life and the second question rates their satisfaction with their own health. The other 24 are divided into physical, psychological, social and environmental domains, each composed of four questions, with scores varying from 1 to 5 on a Likert scale ${ }^{23}$.

The second was the Portuguese version of the World Health Organization Quality of Life - Old (Whoqol-Old) questionnaire, also validated for the Brazilian population ${ }^{24}$, composed of 24 items divided into six facets (domains): sensory functions; autonomy; past, present and future activities; social participation; death and dying; and intimacy, also

composed of four questions per domain, with a Likert scale ranging from 1 to $5^{24}$. In both quality of life instruments, the final score of each domain was calculated using a syntax that classified the total quality of life and each domain of the instrument in percentage scores from 0 to $100^{23,24}$.

Data were collected between September 2016 and February 2017. A team of 14 research assistants was previously trained, and a pilot study was conducted evaluating 16 elderly people from an aqua gymnastics program at a gym in Goiânia.

A significance level of $5 \%(p<0.05)$ was adopted and the data were presented as mean $( \pm s d)$, for the continuous variables, or frequency and percentage for the categorical variables. The normality of the data was verified using the Kolmogorov-Smirnov test. The characterization of the sociodemographic profile of the study and control groups was performed using contingency tables applying the Chi-squared test. To compare the quality-of-life domains evaluated by the Whoqol-Bref and Whoqol-Old, after significant differences in BMI and study time between the SG and the CG were verified and these data were added as covariates to the general linear model, analysis of covariance (ANCOVA) was applied. For the comparisons of the quality of life among the active elderly persons of the SG and the insufficiently active and sedentary elderly of the CG, ANCOVA was used, followed by the Tukey post-test.

The present study was approved by the Research Ethics Committee of the Pontifícia Universidade Católica de Goiás under approval number 1.682.764. All the elderly persons that participated in the study signed a Free and Informed Consent Form.

\section{RESULTS}

The sample of the present study was composed of 108 elderly individuals in the SG and 126 in the CG. The majority of elderly people in the SG $(42.6 \%)$ had been enrolled with AGETUL for more than two years, and the majority (51.9\%) attended programs more than three times a week (Table 1). 
Table 1. Period of enrolment in the Municipal Tourism and Leisure Events Agency (AGETUL) and weekly AGETUL attendance frequency of study group in the city of Goiânia, Goiás, Brazil, 2017.

\begin{tabular}{ll}
\hline AGETUL Information & $\begin{array}{l}\text { Study Group } \\
\mathrm{n}(\%)\end{array}$ \\
\hline Time of enrolment in AGETUL (years) & $29(26.9)$ \\
$\leq 1$ & $33(30.6)$ \\
1 to 2 & $46(42.6)$ \\
$>2$ & \\
Weekly Attendance Frequency at AGETUL & $56(51.9)$ \\
More than 3x/week & $52(48.1)$ \\
\hline Up to 3x/week &
\end{tabular}

The elderly persons in the present study were predominantly aged between 60 and 69 years, and no significant differences were found between the SG and the CG in terms of age groups ( $p=0.27$ ). The majority of the elderly were female and resided in the southern sub-region of Goiânia in both the SG and the CG, with no significant differences between the groups ( $p \geq 0.05)$. The majority of the elderly in the SG had a higher education, while the average educational level in the CG was elementary school $(p=0.009)$. The majority of the elderly persons in both the SG and the CG lived with their families ( $80.6 \%$ and $68.3 \%$, respectively), were retired $(73.1 \%$ and $73.8 \%$, respectively) and did not work (61.1\% and $67.5 \%$, respectively). These findings did not differ significantly between the groups $(p \geq 0.05)$. The family income categories also did not present significant differences between the groups $(p=0.11$ ), while there was a higher frequency of elderly people in the SG with health insurance $(p<0.001)$ (Table 2).

Table 2. Characterization of sociodemographic profile of control and study group. Goiânia, Goiás, Brazil, 2017.

\begin{tabular}{llll}
\hline Sociodemographic Variables & $\begin{array}{l}\text { Study group } \\
\mathrm{n}(\%)\end{array}$ & $\begin{array}{l}\text { Control group } \\
\mathrm{n}(\%)\end{array}$ & $p^{*}$ \\
\hline Age Range (years) & $62(57.4)$ & $59(46.8)$ & 0.27 \\
$60-69$ & $34(31.5)$ & $49(38.9)$ & \\
$70-79$ & $12(11.1)$ & $18(14.3)$ & 0.53 \\
$\geq 80$ & & & \\
\hline Gender & $95(88.0)$ & $114(90.5)$ & 0.86 \\
Female & $13(12.0)$ & $12(9.5)$ & \\
Male & & & \\
\hline Sub-region of residence & $44(34.9)$ & $40(37.0)$ & 0.009 \\
Central/Campinas & $18(14.3)$ & $13(12.0)$ & \\
Southwest & $64(50.8)$ & $55(50.9)$ & \\
South & & $7(5.6)$ & \\
Education & $0(0.0)$ & $49(38.9)$ & \\
Illiterate & $33(30.6)$ & $26(34.9)$ & \\
Elementary School & $37(34.3)$ & & \\
High school & $38(35.2)$ & & \\
Higher education & & & \\
\hline
\end{tabular}


Continuation of Table 2

\begin{tabular}{|c|c|c|c|}
\hline Sociodemographic Variables & $\begin{array}{l}\text { Study group } \\
\mathrm{n}(\%)\end{array}$ & $\begin{array}{l}\text { Control group } \\
\mathrm{n}(\%)\end{array}$ & $p^{*}$ \\
\hline \multicolumn{4}{|l|}{ Lives with } \\
\hline Relatives & $87(80.6)$ & $86(68.3)$ & 0.05 \\
\hline Alone & $20(18.5)$ & $34(27.0)$ & \\
\hline Others & $1(0.9)$ & $6(4.8)$ & \\
\hline \multicolumn{4}{|l|}{ Retired } \\
\hline No & $29(26.9)$ & $33(26.2)$ & 0.90 \\
\hline Yes & $79(73.1)$ & $93(73.8)$ & \\
\hline \multicolumn{4}{|l|}{ Kind of work } \\
\hline Formal & $23(21.3)$ & $16(12.7)$ & 0.21 \\
\hline Informal & $19(17.6)$ & $25(19.8)$ & \\
\hline Does not work & $66(61.1)$ & $85(67.5)$ & \\
\hline \multicolumn{4}{|c|}{ Family Income (Minimum Wage) } \\
\hline Up to 3 & $47(43.5)$ & $68(54.0)$ & 0.11 \\
\hline$>3$ & $61(56.5)$ & $58(46.0)$ & \\
\hline \multicolumn{4}{|l|}{ Health insurance } \\
\hline No & $16(14.8)$ & $44(34.9)$ & $<0.001$ \\
\hline Yes & $92(85.2)$ & $82(65.1)$ & \\
\hline
\end{tabular}

*Chi-squared

The SG had a higher percentage of sufficiently active elderly people $(p<0.001)$. The BMI classification of the individuals differed between the groups $(p=0.002)$, with the majority of the SG considered to be of normal weight and the majority in the CG found to be overweight. The number of falls reported in the last six months was higher in the CG $(p<0.001)$. The percentage of those who declared that they had diseases differed between the SG and CG for hypertension $(p=0.01)$ and thyroid disorders $(p=0.009)$ (Table 3).

The first two questions of the Whoqol-Bref, which refer to how the individual assesses their quality of life and satisfaction with their own health, revealed differences between the groups, with the SG presenting a better perception of quality of life $(p<0.001)$ (Table 4).

The SG had a better quality of life than the CG in all domains of the Whoqol-Bref and the Whoqol-Old $(p<0.05)$. The environmental domain of the WhoqolBref and the autonomy domain of the Whoqol-Old had the lowest mean scores among the elderly of both groups (Table 4).

When comparing total score, questions 1 and 2 and all the domains of the Whoqol-Bref, the active elderly of the SG had higher mean scores than both the IAS and the active elderly persons in the CG $(p<0.05)$. However, when the active and the IAS elderly of the CG were compared no significant differences were found ( $p \geq 0.05)$ (Table 5).

The overall mean and those of the autonomy, past, present and future activities, social participation and intimacy domains of the Whoqol-Old were higher among the active elderly of the SG than among the active and IAS elderly persons of the CG $(p<0.001)$. For the sensory functioning and death and dying domains, the mean scores of the active individuals of the SG were higher than those of the IAS elderly of the CG $(p<0.05)$, while there was no significant difference between the active and the other elderly persons of the CG for these domains $(p \geq 0.05)$ (Table 5). 
Table 3. Comparative analysis of health conditions among study and control groups. Goiânia. Goiás. Brazil. 2017.

\begin{tabular}{llll}
\hline Health condition & $\begin{array}{l}\text { Study group } \\
\mathrm{n}(\%)\end{array}$ & $\begin{array}{l}\text { Control group } \\
\mathrm{n}(\%)\end{array}$ & $p^{*}$ \\
\hline IPAQ & $0(0.0)$ & $85(67.5)$ & $<0.001$ \\
Insufficiently active & $108(100.0)$ & $41(32.5)$ & 0.002 \\
Sufficiently active & & & $10(7.9)$ \\
BMI & $8(7.4)$ & $37(29.4)$ & $<0.001$ \\
Low weight & $56(51.9)$ & $79(62.7)$ & 0.01 \\
Normal weight & $44(40.7)$ & & 0.12 \\
Overweight & & $88(69.8)$ & 0.40 \\
Falls $(6$ months) & $102(94.4)$ & $38(30.2)$ & 0.37 \\
No & $6(5.6)$ & & 0.43 \\
Yes & & $79(61.2)$ & 0.009 \\
\hline Diseases & $50(38.8)$ & $1(20.0)$ & 0.21 \\
Hypertension & $4(80.0)$ & $16(61.5)$ & $4(40.0)$ \\
Cardiopathy & $10(38.5)$ & $17(60.7)$ & $4(23.5)$ \\
Diabetes & $6(60.0)$ & $19(45.2)$ & \\
Osteoporosis & $11(39.3)$ & $13(76.5)$ & \\
Osteoarticular Disorder & $23(54.8)$ & & \\
Thyroid Disorder & & & \\
Other Diseases & & & \\
\hline
\end{tabular}

*Chi-squared.

Table 4. Comparative analysis of quality of life among study and control groups. Goiânia, Goiás, Brazil, 2017.

\begin{tabular}{llll}
\hline $\begin{array}{l}\text { Perception of QoL } \\
\text { Qol Domains }\end{array}$ & Study group & Control group & $p^{*}$ \\
\hline Whoqol-Bref & & & $<0.001$ \\
Q1 & $4.28( \pm 0.67)$ & $3.57( \pm 0.81)$ & $<0.001$ \\
Q2 & $4.02( \pm 0.80)$ & $3.18( \pm 1.02)$ & $<0.001$ \\
Physical & $77.71( \pm 13.80)$ & $61.51( \pm 17.60)$ & $<0.001$ \\
Psychological & $77.74( \pm 11.72)$ & $61.64( \pm 16.39)$ & $<0.001$ \\
Social Relations & $76.08( \pm 15.08)$ & $60.58( \pm 21.17)$ & $<0.001$ \\
Environment & $73.62( \pm 13.94)$ & $57.50( \pm 17.45)$ & $<0.001$ \\
Total score & $76.29( \pm 10.44)$ & $60.30( \pm 15.44)$ & $<0.001$ \\
Whoqol-Old & & & $<0.001$ \\
Sensory Functioning & $83.70( \pm 14.98)$ & $71.63( \pm 17.28)$ & $<0.001$ \\
Autonomy & $75.83( \pm 12.93)$ & $65.91( \pm 13.53)$ & $<0.001$ \\
PPF Activities & $78.15( \pm 11.81)$ & $69.48( \pm 14.53)$ & 0.005 \\
Social participation & $80.83( \pm 11.61)$ & $69.56( \pm 15.39)$ & $<0.001$ \\
Death and Dying & $76.06( \pm 18.76)$ & $68.61( \pm 20.62)$ & $<0.001$ \\
Intimacy & $81.48( \pm 12.39)$ & $69.84( \pm 16.61)$ & $69.17( \pm 11.88)$ \\
Total Score & $79.34( \pm 9.21)$ & & \\
\hline
\end{tabular}

*ANCOVA.Q1=question 1 of Whoqol-Bref - How would you rate your quality of life? Q2=question 2 of Whoqol-Bref - How satisfied are you with your health? 
Table 5. Comparative analysis of quality of life between the sufficiently and insufficiently active elderly persons of the control group and the sufficiently active elderly of the study group, Goiânia, Goiás, Brazil, 2017.

\begin{tabular}{|c|c|c|c|c|}
\hline \multirow{3}{*}{$\begin{array}{l}\text { Perception of QoL } \\
\text { QoL domains }\end{array}$} & Study group & \multicolumn{3}{|l|}{ Control group } \\
\hline & Active Elderly & Active Elderly & IAS & $p^{*}$ \\
\hline & Mean $( \pm s d)$ & Mean $( \pm \mathrm{sd})$ & Mean $( \pm$ sd $)$ & \\
\hline \multicolumn{5}{|l|}{ Whoqol-Bref } \\
\hline Q1 & $4.28( \pm 0.67)^{\mathrm{a}}$ & $3.66( \pm 0.79)^{\mathrm{b}}$ & $3.52( \pm 0.81)^{\mathrm{b}}$ & $<0.001$ \\
\hline Q2 & $4.02( \pm 0.80)^{\mathrm{a}}$ & $3.29( \pm 0.78)^{b}$ & $3.13( \pm 1.09)^{\mathrm{b}}$ & $<0.001$ \\
\hline Physical & $75.33( \pm 17.22)^{\mathrm{a}}$ & $63.24( \pm 17.57)^{\mathrm{b}}$ & $63.69( \pm 16.26)^{b}$ & $<0.001$ \\
\hline Psychological & $74.00( \pm 14.05)^{\mathrm{a}}$ & $63.21( \pm 18.32)^{\mathrm{b}}$ & $65.64( \pm 16.81)^{\mathrm{b}}$ & 0.001 \\
\hline Social Relations & $74.15( \pm 17.35)^{\mathrm{a}}$ & $61.59( \pm 22.12)^{\mathrm{b}}$ & $62.55( \pm 20.19)^{\mathrm{b}}$ & $<0.001$ \\
\hline Environment & $71.77( \pm 15.80)^{\mathrm{a}}$ & $56.49( \pm 17.88)^{\mathrm{b}}$ & $60.35( \pm 17.14)^{b}$ & $<0.001$ \\
\hline Total score & $73.81( \pm 13.19)^{a}$ & $61.13( \pm 16.68)^{\mathrm{b}}$ & $63.06( \pm 15.02)^{\mathrm{b}}$ & $<0.001$ \\
\hline \multicolumn{5}{|l|}{ Whoqol-Old } \\
\hline Sensory Functioning & $83.70( \pm 14.46)^{\mathrm{a}}$ & $77.68( \pm 15.78)^{\mathrm{a}, \mathrm{b}}$ & $68.71( \pm 17.86)^{\mathrm{b}}$ & $<0.001$ \\
\hline Autonomy & $75.79( \pm 13.49)^{\mathrm{a}}$ & $67.44( \pm 12.20)^{\mathrm{b}}$ & $65.24( \pm 13.49)^{\mathrm{b}}$ & $<0.001$ \\
\hline PPF Activities & $78.80( \pm 11.62)^{\mathrm{a}}$ & $72.20( \pm 13.51)^{\mathrm{b}}$ & $67.35( \pm 14.49)^{\mathrm{b}}$ & $<0.001$ \\
\hline Social participation & $81.62( \pm 11.19)^{\mathrm{a}}$ & $72.07( \pm 14.70)^{\mathrm{b}}$ & $67.32( \pm 15.16)^{\mathrm{b}}$ & $<0.001$ \\
\hline Death and Dying & $76.30( \pm 18.89)^{\mathrm{a}}$ & $69.15( \pm 20.55)^{\mathrm{a}, \mathrm{b}}$ & $68.06( \pm 20.50)^{b}$ & 0.017 \\
\hline Intimacy & $81.25( \pm 13.98)^{\mathrm{a}}$ & $71.95( \pm 14.14)^{\mathrm{b}}$ & $69.12( \pm 16.31)^{b}$ & $<0.001$ \\
\hline Total Score & $79.58( \pm 9.23)^{\mathrm{a}}$ & $71.75( \pm 10.65)^{\mathrm{b}}$ & $67.63( \pm 11.99)^{\mathrm{b}}$ & $<0.001$ \\
\hline
\end{tabular}

*ANCOVA; a,b=Tukey post-hoc test for multiple comparisons between the active elderly persons of the study group and the active and insufficiently active and sedentary elderly of the control group; QoL = Quality of Life; IAS = Insufficiently active and sedentary; Q1 = Whoqol-Bref question 1 - How would you rate your quality of life? Q2 = Whoqol-Bref question 2 - How satisfied are you with your health?

\section{DISCUSSION}

The quality of life scores of the elderly persons of the SG who participated in physical exercise programs was better in all the domains of the Whoqol-Bref and Whoqol-Old instruments (Table 4) and in terms of the overall mean, even when compared with only the active elderly members of the control group, which is one of the main findings of the present study. These results indicate the importance of programs of this nature aimed at the elderly population, and agree with studies that have indicated an association between quality of life and the practice of exercise in groups of elderly people ${ }^{9,16}$.

Quality of life is a subjective concept, related to aspects such as functional capacity, emotional state, family support, health status, socioeconomic level, intellectual activity, satisfaction with the environment in which one lives and with activities of daily living ${ }^{25}$, which are analyzed by the domains of the instruments used. In these aspects the elderly of the SG had higher scores for all the domains (Table 4).
With advancing age there is an increase in functional disorders and chronic conditions ${ }^{26}$, which highlights the importance of considering the impact of functional capacity on the quality of life of the elderly. A better mean score in the physical domain was perceived among the elderly participants of the physical exercise programs $(p$ $<0.001)$, a result that corroborates recent studies ${ }^{27,28}$. Evidence has indicated that exercise can influence and reduce the risk of developing chronic diseases, including cardiovascular disease, hypertension, osteoporosis, obesity and cognitive impairment, as well as increasing aerobic capacity, muscle strength and other variables of physical fitness ${ }^{20}$.

This influence could be seen in the analysis of the health conditions of the studied groups, as the SG had a higher percentage of elderly persons with normal weight $(p=0.002)$, a lower rate of falls in the last six months $(p<0.001)$ and a lower prevalence of hypertensive elderly $(p=0.01)$ (Table 3 ), thus demonstrating the importance and impact of public physical exercise programs. These results are in line 
with the guidelines of the National Health Policy of the Elderly, which stresses the need to promote active aging, seeking to maintain the functional capacity and autonomy of such individuals ${ }^{29}$.

In the present study, the elderly of the SG had higher means for the psychological, social relations, social participation and intimacy domains $(p<0.001)$ (Table 4). The higher scores in these domains can be attributed to the fact that the activities offered provide opportunities for social relationships, thus contributing to the exchange of experiences and the emergence of new affective bonds. Recent research has also found that elderly people who participated in physical exercise programs had higher scores in these domains than those in the control group ${ }^{6,8,28,30}$.

The practice of physical exercises can improve self-esteem, body image and inspire pride in their appearance among elderly persons, aspects which may be related to factors such as weight reduction or the possibility of new affective relationships ${ }^{31}$. In this sense, participation in group activities, such as public physical exercise programs, plays an important role in the quality of life of the elderly, as such activities can also contribute to individuals feeling as though they are participating agents of community life ${ }^{18}$.

Factors related to leisure opportunities, health care, physical infrastructure, financial resources and safety are included in the environmental domain ${ }^{23}$. In this study, the SG had higher scores in this domain than the CG $(p<0.001)$. This result differed from a survey conducted with 54 elderly women in Nice, France, where after 12 weeks of a physical activity program there were no differences in relation to the control group ${ }^{28}$. However, differences in the values obtained in this domain can be explained by the different environmental circumstances of each country ${ }^{12}$.

The sensory functioning domain evaluates the impact of the decline of sensory abilities, such as loss of hearing, touch, sight, taste and smell ${ }^{24}$, on quality of life, with these losses closely linked to frailty among the elderly ${ }^{12}$. The fact that the elderly of the SG had higher scores in this domain than the CG $(p<0.001)$ (Table 4), can be attributed to the effects of physical exercise, such as the optimization of blood flow in the sensory system ${ }^{32}$, an increase in brain volume, the elevation of neurotrophic factors derived from the brain and improvements in neurotransmitter systems, resulting in good perceptual functioning ${ }^{20}$. Evidence has indicated an association between health problems and the sensory functioning and death and dying domains ${ }^{10}$. This may be the explanation for the higher scores of the SG elderly in these domains, as the CG had a higher rate of insufficiently active $(p<0.001)$ and overweight $(p=0.002)$ elderly persons, those who had fallen in the last semester $(p<0.001)$ and hypertensive patients ( $p=0.01)$ (Table 3).

The SG had higher scores than the CG in the autonomy domain $(p<0.001)$ (Table 4$)$. This domain considers the freedom the elderly person has to make their own decisions, the control they feel they have over their future, the respect for their freedom of the people close to them, and the ability to do the things they would like to $\mathrm{do}^{24}$. Another recent study obtained similar results to the present study, where elderly people who performed physical exercises had better scores for this domain ${ }^{6}$. The regular practice of exercises gives the elderly better knowledge of their own body, as well as their aptitudes and limitations ${ }^{33}$. This corroborates with the results of the present study, since the majority of the SG had been enrolled in the program for more than two years $(42.6 \%)$ and attended the program more than three times a week $(51.9 \%)$ (Table 1).

Recent studies did not find higher scores for the present, past and future activities domain among elderly persons who performed physical exercises ${ }^{8,30}$, unlike the findings of the present study, where the SG did achieve higher scores $(p<0.001)$ (Table 4). While it is clear that the past satisfaction and achievements of a person cannot be altered, the regular practice of physical exercises can beneficially modify the future expectations of an individual, and further research is needed to clarify this issue.

When comparing the elderly persons of the SG and the CG in terms of physical activity, it was found that the SG had better quality of life scores for all the domains of the Whoqol-bref $(p<0.05)$ (Table 4$)$, even in comparison with the active elderly persons of the CG. Regarding the Whoqol-Old instrument, the elderly of the SG had higher average scores for the autonomy, past, present and future activities, social participation and intimacy domains and the overall category than the active and the IAS elderly of the CG 
$(p<0.05)$, and for the sensory functioning and death and dying domains for the IAS of the CG $(p<0.05)$ (Table 5). These results suggest that the practice of physical exercise can be a determining factor for a better perception of quality of life. A recent study with 50 elderly persons found that those who participated in a guided exercise program had a better quality of life than those who did not participate, and that physically active non-participants did not have a better quality of life than insufficiently active non-participants ${ }^{34}$.

No significant differences were found between the active and IAS elderly persons of the CG for the total score or any Whoqol-Bref domain. In terms of the Whoqol-Old, no differences were found between the active and IAS elderly of the CG in the mean scores of any domain or in the total score $(p \geq 0.05)$ (Table 5). Another study has observed that the perception of quality of life did not differ between the active and sedentary elders ${ }^{35}$. These results suggest that the level of physical activity may not be sufficient for the elderly to present a better quality of life.

This study has some limitations, such as the transversal nature of the research. New research with a longitudinal methodology may contribute to the understanding of other aspects that are relevant to the analysis of the quality of life of elderly participants in public exercise programs, such as the types of activities performed, the place they are carried out, and also the frequency of the exercise programs.

\section{CONCLUSION}

The elderly participants of public physical exercise programs had a better perception of quality of life in all the domains of the Whoqol-bref and Whoqol-old. Active elderly people in public programs had a better quality of life than non-participating active persons in all the Whoqol-bref domains, and for the autonomy, past, present and future activities, social participation and intimacy domains of the Whoqol-old.

In conclusion, there are significant differences between the quality of life of elderly persons who participated in and did not participate in public physical exercise programs, while simply being physically active may not be enough to have a better perception of quality of life. This suggests that other factors related to the life of the elderly and participation in public exercise programs may be related to a better quality of life. Adherence to public exercise programs can therefore contribute to maintaining or improving the quality of life of the elderly.

\section{REFERENCES}

1. Unated Nations. World population ageing 2015. New York: UN; 2015.

2. Instituto Brasileiro de Geografia e Estatística. Síntese de indicadores sociais: uma análise das condições de vida da população brasileira. Rio Janeiro: IBGE; 2016.

3. Sundstrup E, Jakobsen MD, Andersen LL, Andersen TR, Randers MB, Helge JW, et al. Positive effects of 1-year football and strength training on mechanical muscle function and functional capacity in elderly men. Eur J Appl Physiol. 2016;116(6):1127-38.

4. Silva PA, Soares SM, Santos JF, Silva LB. Cut-off point for WHOQOL-bref as a measure of quality of life of older adults. Rev Saúde Pública. 2014;48(3):390-7.

5. Silva AR, Sgnaolin V, Nogueira EL, Loureiro F, Engroff $\mathrm{P}$, Gomes I. Doenças crônicas não transmissíveis e fatores sociodemográficos associados a sintomas de depressão em idosos. J Bras Psiquiatr. 2017;66(1):45-51.
6. Ferretti F, Beskow GCT, Slaviero RC, Ribeiro CG. Análise da qualidade de vida em idosos praticantes e não praticantes de exercício físico regular. Estud Interdiscip Sobre o Envelhec. 2015;20(3):729-43.

7. World Health Organization Quality Of Life Group. Development of the WHOQOL - Rationale and current status. Int J Ment Health. 1994;23(3):24-56.

8. Da Fonte E, Feitosa PH, De Oliveira Neto LT, De Araújo CL, Figueiroa JN, Alves JG. Effects of a physical activity program on the quality of life among elderly people in Brazil. J Fam Med Prim Care. 2016;5(1):139-42.

9. Vagetti GC, Barbosa Filho VC, Moreira NB, De Oliveira V, Mazzardo O, De Campos W. The Association between Physical Activity and Quality of Life Domains among Older Women. J Aging Phys Act. 2015;23(4):524-33. 
10. Vagetti GC, Barbosa Filho VC, Moreira NB, De Oliveira V, Mazzardo O, Campos W. Health conditions and sociodemographic variables associated with quality of life in elderly women from a physical activity program in Curitiba, Paraná State, Southern Brazil. Cad Saúde Pública. 2013;29(5):955-69.

11. Barbosa AP, Gomes Teixeira T, Orlandi B, Teixeira $\mathrm{N}$, De Oliveira B, Villas MH, et al. Level of physical activity and quality of life: a comparative study among the elderly of rural and urban areas. Rev Bras Geriatr Gerontol. 2015;18(4):743-54.

12. Haider S, Luger E, Kapan A, Titze S, Lackinger C, Schindler K, et al. Associations between daily physical activity, handgrip strength, muscle mass, physical performance and quality of life in prefrail and frail community-dwelling older adults. Qual Life Res. 2016;25(12):3129-38.

13. Ribeiro CG, Ferretti F, De Sá CA. Quality of life based on level of physical activity among elderly residents of urban and rural areas. Rev Bras Geriatr Gerontol. 2017;20(3):330-9.

14. Bombardelli C, Telles LH, Rosa D, Keller KD, Da P, Klahr S, et al. Quality of life of elderly people living in a municipality with rural characteristics in the countryside of Rio Grande do Sul. Rev Bras Geriatr Gerontol. 2017;20(1):88-94.

15. Vélez Álvarez C, Del Pilar M, Potes E, Eugenia M, Merchán P, Consuelo C, et al. Quality of life and informal labor among elderly persons in an intermediate Colombian city. Rev Bras Geriatr Gerontol. 2016;19(3):415-27.

16. Vagetti GC, Barbosa Filho VC, Lia N, Moreira B, De Oliveira V, Mazzardo O, et al. Association between physical activity and quality of life in the elderly: a systematic review, 2000-2012. Rev Bras Psiquiatr. 2014;36(1):76-88.

17. Battaglia G, Bellafiore M, Alesi M, Antonio Paoli, Bianco A, Palma A. Effects of an adapted physical activity program on psychophysical health in elderly women. Clin Interv Aging. 2016;11:1009-15.

18. Brasil. Ministério da Saúde. Avaliação de efetividade de programas de Atividade Física no Brasil. Brasília, DF:MS; 2013.

19. Dhanak M, Penhall R. Australian and New Zealand Society for geriatric medicine: Position statement: exercise guidelines for older adults. Aust J Ageing. 2014;33(4):287-94

20. Chodzko-Zajko WJ, Proctor DN, Fiatarone Singh MA, Minson CT, Nigg CR, Salem GJ, et al. Exercise and physical activity for older adults. Med Sci Sport Exerc. 2009;41(7):1510-30.
21. Melo DM, Barbosa AJG. O uso do Mini-Exame do Estado Mental em pesquisas com idosos no Brasil: uma revisão sistemática. Ciênc Saúde Coletiva. 2015;18(4):3865-76.

22. Matsudo S, Araújo T, Matsudo V, Andrade D, Andrade E, Oliveira LC, et al. International physical activity questionnaire (IPAQ): study of validity and reliability in Brazil. Rev Bras Ativ Fís Saude. 2001;6(2):5-18.

23. Fleck MP, Louzada S, Xavier M, Chachamovich E, Vieira G, Santos L, et al. Application of the Portuguese version of the abbreviated instrument of quality life WHOQOL-bref. J Public Health. 2000;34(2):178-83.

24. Fleck MP, Chachamovich E, Trentini C. Development and validation of the Portuguese version of the WHOQOL-OLD module. Rev Saúde Pública. 2006;40(5):785-91.

25. Dawalibi NW, Goulart RMM, Prearo LC. Factors related to the quality of life of the elderly in programs for senior citizens. Ciênc Saúde Coletiva. 2014;19(8):3505-12.

26. Vagetti GC, Moreira NB, Barbosa Filho VC, De Oliveira V, Cancian CF, Mazzardo O, et al. Domínios da qualidade de vida associados à percepção de saúde: um estudo com idosas de um programa de atividade física em bairros de baixa renda de Curitiba, Paraná, Brasil. Ciênc Saúde Coletiva. 2013;18(12):3483-93.

27. Chaves Aveiro M, Driusso P, Dos Santos JG, Kiyoto VD, Oishi J. Effects of a physical therapy program on quality of life among community-dwelling elderly women: randomized-controlled trial. Fisioter Mov. 2013;26(3):503-13.

28. Émile M, Chalabaev A, Pradier C, Clément-Guillotin C, Falzon C, Colson SS, et al. Effects of supervised and individualized weekly walking on exercise stereotypes and quality of life in older sedentary females. Sci Sports. 2014;29(3):15-63.

29. Brasil. Portaria n. 2.528, de 19 de outubro de 2006. Aprova a Política Nacional de Saúde da Pessoa Idosa e determina outras providências. Saúde Legis. 20 out. 2006. p. 1-12.

30. Figueira HA, Figueira AA, Cader SA, Guimarães AC, De Oliveira RJ, Figueira JA, et al. Effects of a physical activity governmental health programme on the quality of life of elderly people. Scand J Soc Med. 2012;40(5):418-22.

31. Fonseca CC, Chaves ECL, Pereira SS, Barp M, Moreira AM, Nogueira DA. Autoestima e satifação corporal em idosas praticante e não praticantes de atividades corporais. J Phys Educ. 2014;25(3):429-39. 
32. Mann L, Kleinpaul JF, Mota CB, Maria FDS, Maria S. Equilíbrio corporal e exercícios físicos : uma revisão sistemática. Motriz. 2009;15(3):713-22.

33. De Oliveira AC, Oliveira NMD, Arantes PMM, Alencar MA. Qualidade de vida em idosos que praticam atividade física: uma revisão sistemática. Rev Bras Geriatr Gerontol. 2010;13(2):301-12.
34. Silva MFS, Goulart NBA, Lanferdini FJ, Marcon M, Dias CP. Relação entre os níveis de atividade física e qualidade de vida de idosos sedentários e fisicamente ativos. Rev Bras Geriatr Gerontol. 2012;15(6):635-42.

35. Alencar NAA, De Souza Júnior JV, Aragão JCB, Dantas E. Nivel de atividade física, autonomia funcional e qualidade de vida em idosas ativas e sedentárias. Fisioter Mov. 2010;23(3):473-81. 